\title{
Commentary: Kidney at the heart of the matter
}

\author{
Osami Honjo, MD, $\mathrm{PhD},{ }^{\mathrm{a}, \mathrm{b}}$ and \\ Anne I. Dipchand, $\mathrm{MD}^{\mathrm{c}}$
}

Significant renal insufficiency (SRI) in pediatric patients with progressive heart failure is common, and may affect transplant candidacy and potentially compromise early and late outcomes after heart transplant. Simultaneous heartkidney transplant (HKTx) has been shown to be an effective treatment strategy for selected patients with end-stage heart failure and SRI, but it has rarely been done in pediatric populations. $^{1,2}$ Dani and colleagues ${ }^{3}$ conducted a large-scale study using United Network for Organ Sharing Registry data spanning more than 3 decades to determine whether or not listing for HKTx is superior to listing for heart transplantation (HTx) alone in patients with SRI. The study is the largest and most comprehensive clinical series of pediatric HKTx to date and conveys some important messages.

The comparison between 109 patients who were listed for HKTx and 318 patients with SRI for HTx alone showed significantly better 1 - and 5 -year posttransplantation survival in patients who received HKTx than patients with SRI who received HTx alone. The data should be carefully interpreted because the patients with SRI who were listed for HTx alone were significantly younger, tended to have congenital heart disease, and were sicker with higher rates of inotropes, ventilation, and extracorporeal membrane oxygenation at the time of listing. As the authors also indicated, those risk factors may have influenced the lower

From the ${ }^{\mathrm{a}}$ Division of Cardiovascular Surgery and ${ }^{\mathrm{c}}$ Department of Pediatrics, Labatt Family Heart Centre, The Hospital for Sick Children, Toronto, Ontario, Canada; and ${ }^{\mathrm{b}}$ Department of Surgery, University of Toronto, Toronto, Ontario, Canada.

Disclosures: The authors reported no conflicts of interest.

The Journal policy requires editors and reviewers to disclose conflicts of interest and to decline handling or reviewing manuscripts for which they may have a conflict of interest. The editors and reviewers of this article have no conflicts of interest.

Received for publication Dec 21, 2021; revisions received Dec 21, 2021; accepted for publication Dec 22, 2021; available ahead of print Dec 27, 2021.

Address for reprints: Osami Honjo, MD, PhD, Division of Cardiovascular Surgery, Labatt Family Heart Center, The Hospital for Sick Children, 555 University Ave, Toronto, Ontario M5G 1X8, Canada (E-mail: osami.honjo@sickkids.ca).

J Thorac Cardiovasc Surg 2022;164:2034-5 $0022-5223 / \$ 36.00$

Copyright $₫ 2021$ Published by Elsevier Inc. on behalf of The American Association for Thoracic Surgery

https://doi.org/10.1016/j.jtcvs.2021.12.044

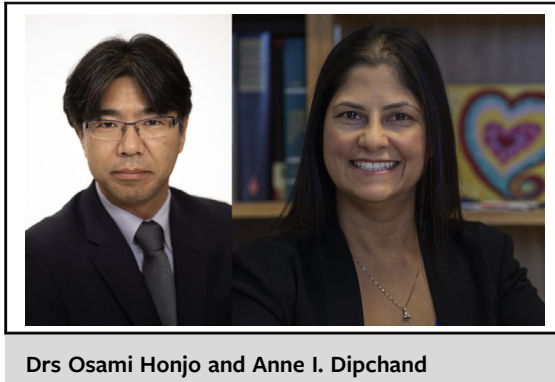

CENTRAL MESSAGE

Heart-kidney transplant in

selected patients with persistent renal failure, and heart transplant

alone in patients with recovered renal function, are both effective strategies.

posttransplantation survival in that group seen in this study. The patients with SRI who were listed for HTx alone had more than twice the waitlist mortality, also reflecting the acuity of this patient group.

Perhaps among the most important messages from this study is that among the patients with SRI who were listed for HTx, more than $70 \%$ had improved renal function (estimated glomerular filtration rate $>40 \mathrm{~mL} / \mathrm{min}$ ) at the time of HTx. Furthermore, the patients with improved renal function who received HTx had an equivalent survival rate compared with the patients who received HKTx. This underscores the importance of re-evaluation of renal function among the patients who were listed for HKTx and a low threshold to convert to HTx listing when renal function recovers. This also emphasizes the importance of ongoing optimization of renal function among the listed patients, which ultimately improves post-HTx outcomes.

HKTx listing has increased since 2001 but it is still a very small fraction of the patients who need HTx.$^{1-3}$ There have been few experiences with HKTx in infants and small children. Potential disadvantages of HKTx listing are much longer waiting period (101 vs 39 days) compared with HTx alone listing, and the lack of ability to predict renal functional recovery among the patients with SRI, which may lead to unnecessary multiorgan transplantation in patients with renal functional recovery potential. ${ }^{4}$ This 
study certainly gives some insights into the dilemma of SRI in pediatric HTx candidates, both from HKTx outcome and renal functional recovery points of view, and the authors should be congratulated on conducting a highly influential study.

\section{References}

1. Rossano JW, Cherikh WS, Chambers DC, Goldfarb S, Hayes D Jr, Khush KK, et al. The International Thoracic Organ Transplant Registry of the International Society for Heart and Lung Transplantation: twenty-first pediatric heart transplantation report-2018; focus theme: multiorgan transplantation. J Heart Lung Transplant. 2018;37:1184-95.

2. Weng PL, Alejos JC, Halnon N, Zhang Q, Reed EF, Tsai Chambers E. Long-term outcomes of simultaneous heart and kidney transplantation in pediatric recipients. Pediatr Transplant. 2017;21. https://doi.org/10.1111/petr.13023

3. Dani A, Price N, Thangappan K, Ryan TD, Hooper DK, Cooper DS, et al. Heart-kidney listing is better than isolated heart listing for pediatric heart transplant candidates with significant renal insufficiency. J Thorac Cardiovasc Surg. 2022;164:2019-31.

4. Shaw BI, Sudan DL, Boulware LE, McElroy LM. Striking a balance in simultaneous heart 458 kidney transplant: optimizing outcomes for all wait-listed patients. J Am Soc Nephrol. 2020;31:1661-4. 